\title{
استراتيجية تنال القمر ودورها في تلدريس الأحاديث النبوية الشريفة لتلاميذ المرحلة الإعدادية الأزهرية
}

\author{
إعـــلداد
}

د ميهي نشأت عبدالرازق

مدرس المناهج وطرق تدريس اللغة العربية

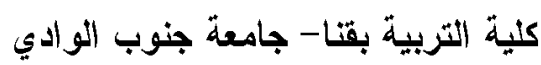

memenashat@edu.svu.edu.eg
أ.د سيد السيايع حمدان

أستاذ المناهج وطرق تلريس اللغة العربية

ووكيل الكلية لشئون التعليم والطلاب سابقاً sayedhamdan@edu.svu.edu.eg

\footnotetext{
أ / شاذلي أحمل محمد أحمل علي

باحث ماجستير قسم المناهج وطرق التدريس

كلية التربية بقنا- جامعة جنوب التوادي لوبي

Shazliahmed593@gmail.com
} 
استراتيجية تنال القمر ودورها في تدريس الأحاديث النبوية الثريفة لتلاميذ المرحلة الإعدادية الأزهرية أ أشاذلي أحمد محمد أحمد علي الأية

\title{
استراتيجية تنال القمر ودورها في تدريس الأحاديث النبوية الشريفة لتلاميذ المر حلة الإعدادية الأزهرية
}

\author{
إعداد
}

د ميمي نشأت عبدالرازق

مدرس المناهج وطرق تلدريس اللغة العربية

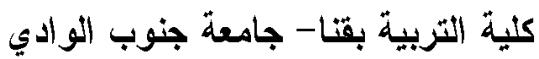

memenashat@edu.svu.edu.eg

\section{أ.د أسيد السايح حمدان}

أستاذ المناهج وطرق تدريس اللغة العربية ووكيل الكلية لشئون التعليم والطلاب سابقاً sayedhamdan@edu.svu.edu.eg

\section{أ / شاذلي أحمد محمد أحمد علي \\ باحث ماجستير قسم المناهج وطرق التدريس

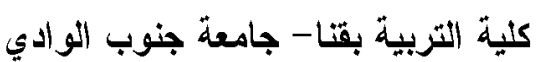 \\ Shazliahmed593@gmail.com}

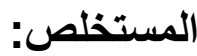

يُعد الحديث النبوي الثريف المصدر الثاني من مصادر الثريعة الإسلامية، كما يعد

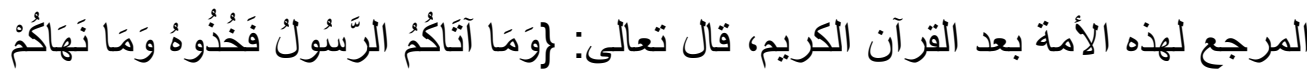

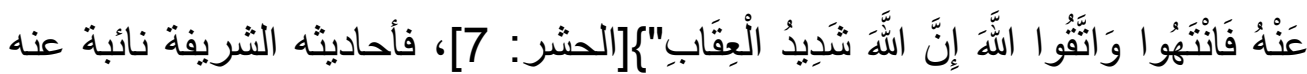
وقائمة مقامه، فهي خير مربٍ للناس، و أفضل مُصلحِ للأجيال فليس بعد كلام الله أفضل

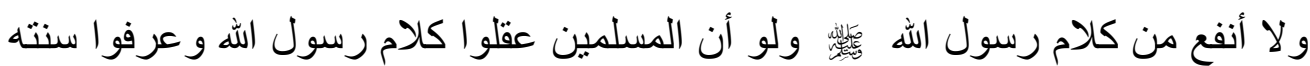

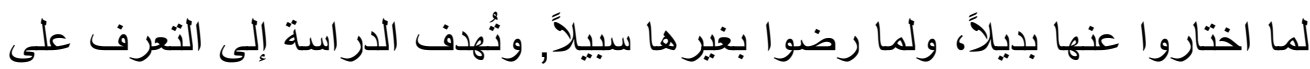
استراتيجية تنال القمر ودورها في تدريس الأحاديث النبوية الثريفة لتلاميذ الصف الأول الإعدادي الأزهري, وتم استخدام المنهج شبه التجريبي والذي يعتمد على التصميم التجريبي ذي المجمو عة الواحدة ذات القياسين القبلي و البعدي, وأن عدد أفر اد مجمو عة البحث (32) تلميذاً من تلاميذ الصف الأول الإعدادي الأزهري. الكلمات مفتاحية: استراتيجية تنال القر, الحديث النبوي الثريف, تلاميذ المرحلة الإعدادية الأز هرية. 
استراتيجية تنال القمر ودورها في تدريس الأحاديث النبوية الثريفة لتلاميذ المرحلة الإعدادية الأزهرية أ أشاذلي أحمد محمد أحمد علي الازية

\section{Strategy of Tanal Al-Kamar and its Role in Teaching the Prophet's Hadith for Students of Al-Azhar Preparatory Stage}

\section{Prepared by:}

Prof. Sayed Al-Sayeh Hamdan

Prof. Methods, Curricula of Arabic Language

(Former)Vice-dean of Qena Faculty of

Education for Students' Affairs and Education

sayedhamdan@edu.svu.edu.eg
Dr. Memi Nashaat Abdelrazek

Methods ,Curricula of Arabic Language

Qena Faculty of Education - South

Valley University

memenashat@edu.svu.edu.eg

\section{Shazly Ahmed Mohamed Ahmed Ali}

An M.A. Researcher in Methods and Curricula of Arabic Language

Qena Faculty of Education - South Valley University

Shazliahmed593@gmail.com

\section{Abstract:}

The Prophet's Hadith is regarded as the second source of Islamic Sharia, it is also regarded as the reference of the Islamic nation after the Holy Quran as Allah, in the Holy Quran, says "And whatever the Messenger has given you - take; and what he has forbidden you - refrain from. And fear Allāh; indeed, Allāh is severe in penalty" (Al-Hashr: 7). The Prophet's Hadith are representatives of the prophet himself. The Prophet's Hadith is the best educator of people and the best reformer of generations. In addition, if Muslims think deeply and understand the Prophet's Hadith, they would never use any other alternatives in their life.The current study aims at investigating strategy of Tanal Al-Kamar and its role in teaching the Prophet's Hadith for students of Al-Azhar preparatory stage, The Semi- experimental Curriculum has been used Which depends on experimental design with one group that has two before and after measurements, The number of research group individuals are thirty-two Students from Students of Al-Azhar first preparatory grade.

Key wards: Strategy of Tanal Al-Kamar- the Prophet's Hadith- Students of Al-Azhar Preparatory Stage. 
استراتيجية تنال القمر ودورها في تدريس الأحاديث النبوية الثريفة لتلاميذ المرحلة الإعدادية الأزهرية

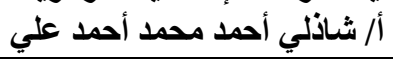

يُعد الحديث النبوي الثريف المصدر الثاني من مصـادر التشريع الإسلامي بعد التهد

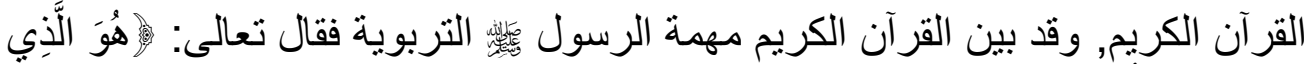

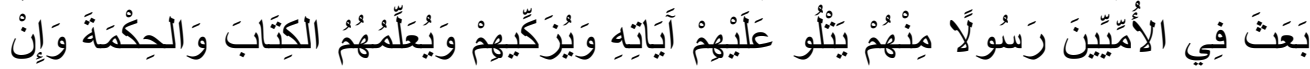

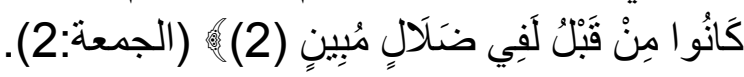
وجاء الدور التربوي للحديث النبوي مكملاً ومفصلاً ومطبقاً لما جاء في القرآن

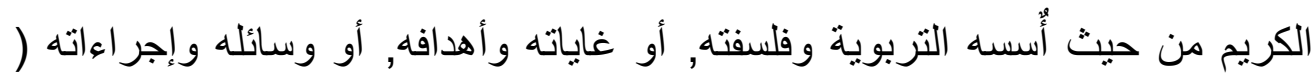

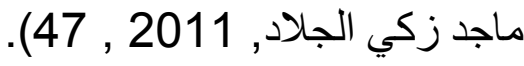

ويمثل الرسول الكريم الأسوة والقدوة الحسنة, ويجب علينا طاعته والامتثال لأو امره, واجتناب ما نهانا عنه, فقد ورد في كلام الله تعالى عنه: إلَقَّْ كَانَ لَكُمْ فِي

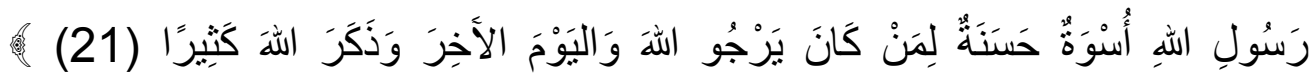

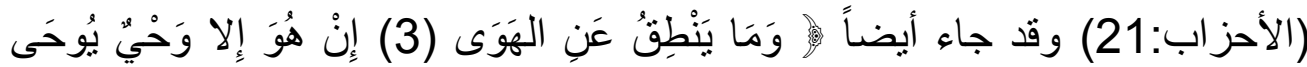
(4-3) (4) (4) (4) (4)

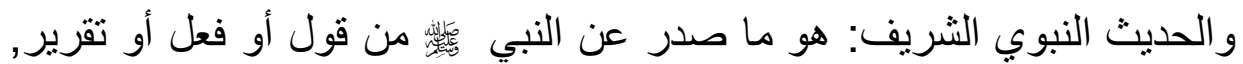

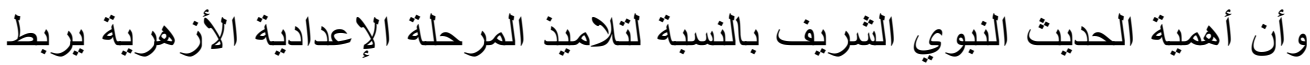

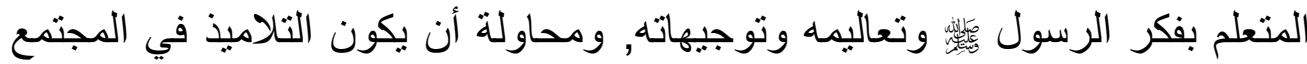

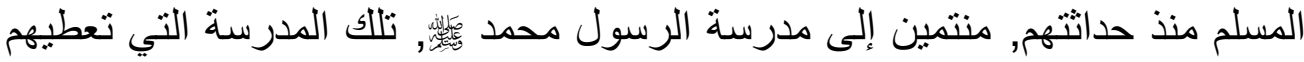

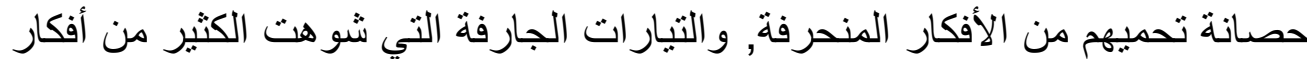

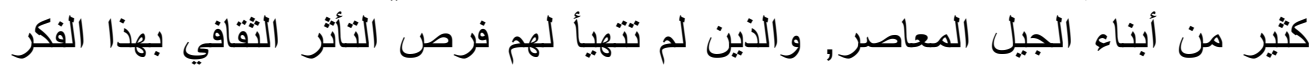

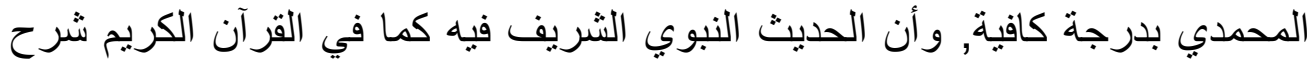
وتفسير وتوضيح لكثير من مبادئ الإسلام وتثريعاته, وفيه كذلك الكثير من معالم

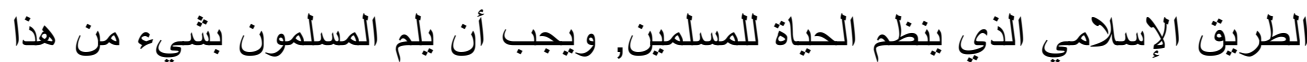

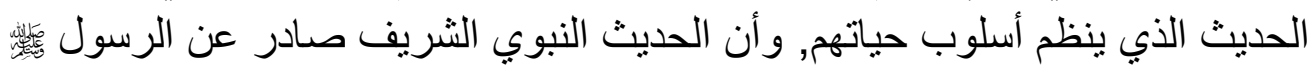
وهو من هو قيادة وحكمة وسلوكاً, ودر استه بإمعان وفهم تسهم في تكوين التلميذ خلقياً

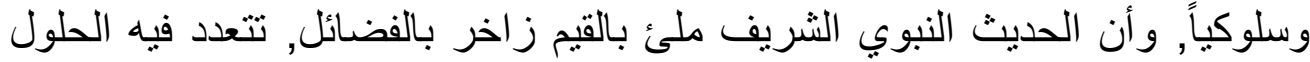
لكثير من مشكلات الحياة و الناس و الكون, وفي هذا راحة للنفس و اطمئنان للقلب (محمد صلاح الدين علي مجاور , 1976, 323). 
استراتيجية تنال القمر ودورها في تدريس الأحاديث النبوية الثريفة لتلاميذ المرحلة الإعدادية الأزهرية أ أشاذلي أحمد محمد أحمد علي الأية

دراسات تتعلق بالأحاديث النبوية الثريفة:

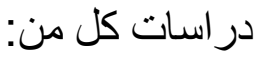

در اسة محمد عبداله حسين الحازمي (2013):

هدفت الدراسة إلى بيان طرق التدريس التي استخدمها الرسول فالس كالعبادات

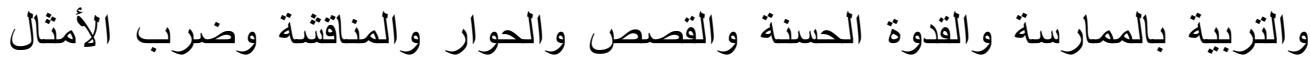
و الترغيب و الترهيب و الوعظ, و هذا ما يؤكد أننا بحاجة إلى استخدام طر ائق و أساليب فعالة في تدريس مقرر الحديث النبوي الثريف لمو اجهة التحديات التي يوجهها المتعلم من مجتمعه ومن حوله.

دراسة عبدالله نعمة الثمري (2010):

توصلت الدراسة إلى أن اكتفاء الكثير من معلمي الأحاديث النبوية الثريفة

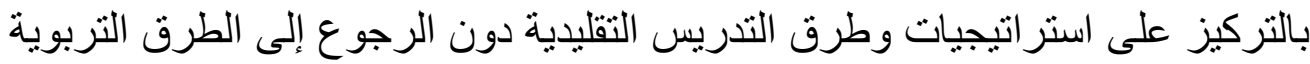
المناسبة يؤدي إلى عدم الالتفات إلى الحصيلة المعرفية و المفاهيم الحقيقية للتناميذ. وأن السبب في هذا الضعف بأنه ناتج عن عدم اتباع المعلمين لطر ائق حديثة في

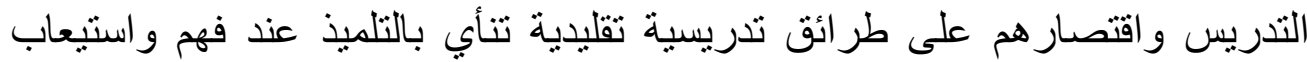
الأحاديث النبوية الثريفة, وتجعله يعتمد على حفظ المادة و استظهار ها للاختبار فقط. لذا سعى البحث الحالي استخدام استر اتيجية تنال القمر في تدريس الأحاديث النبوية

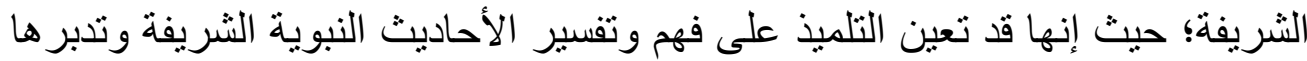
واستتناج الدروس و العبر المستفادة منها.

وتبرز أهمية استراتيجية تنال القمر, تللك الاستراتيجية التي تتكون من خمس

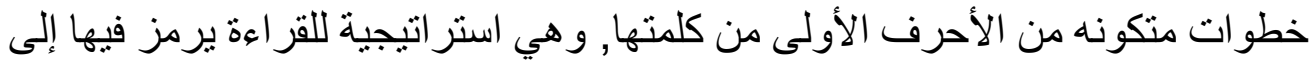

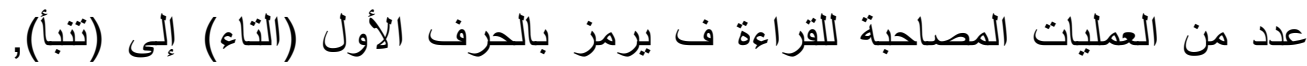

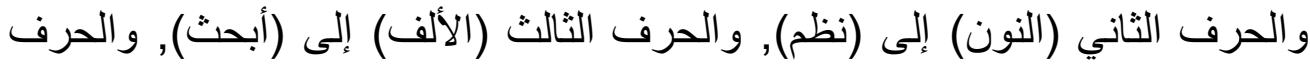

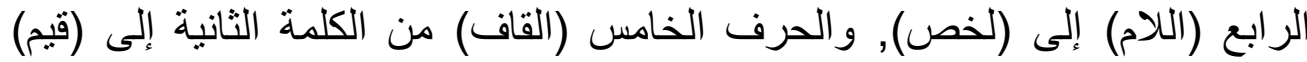
(إلهام بنت عبدالعزيز الغنام, 2013) (لفص), 10).

وبشكل عام فإن هذه الاستر اتيجية للقر اءة تسمح للتلاميذ أن يصبحو ا متفاعلين بنحو كبير في النص القرائي, وكذللك بناء معرفتهم السابقة (محسن علي عطية التية. 
استراتيجية تنال القمر ودورها في تدريس الأحاديث النبوية الثريفة لتلاميذ المرحلة الإعدادية الأزهرية أ أشاذلي أحمد محمد أحمد علي الأية

بعض الاراسات التي أثبتت نتائج أهمية الاستراتيجية وفاعليتها:

Adeniyi, در اسة رافائيل (2001) , Rapheal , ودراسة اديني (2000) ودراسة صوفيا فيصل الهياجنة, وشادية أحمد التل (2017) (2016), ودراسة إيناس جهاد

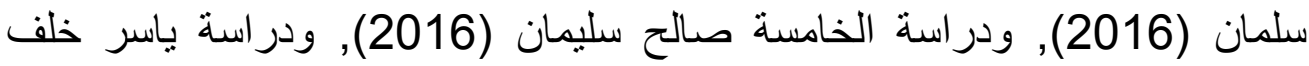

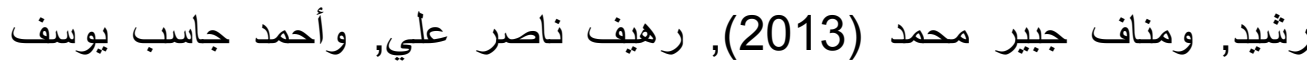

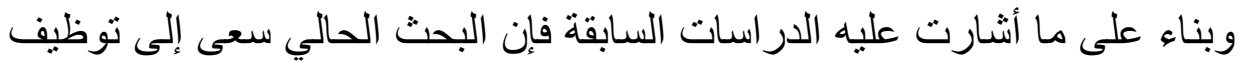

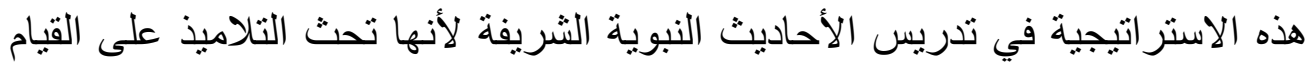

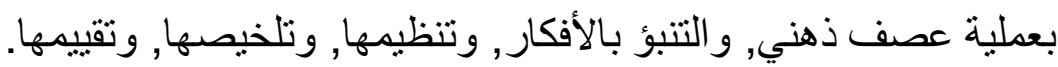

ومما سبق يستتتج الباحث أن استر اتيجية تنال القمر تساعد التلميذ على استيعاب ما يقرؤه, ويحتفظ بقدر كبير من المعلومات في ذهنه, ليتمكن من توظيف واستخدام هذه إنه

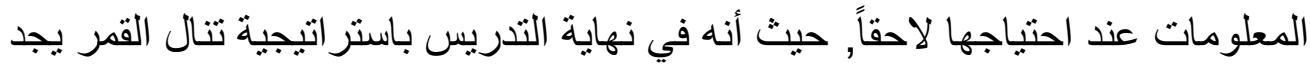

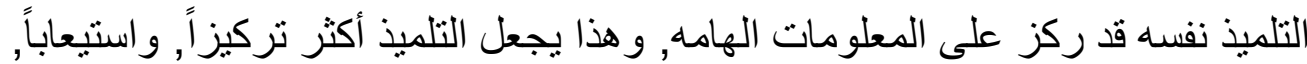
وشعوراً بالإنجاز .

مشكلة البحث: "ضعف لاى التلاميذ في الأحاديث النبوية الشريفة". سؤال البحث: ما فاعلية استراتيجية تنال القمر في تدريس الأحاديث النبوية الثريفة

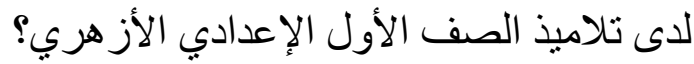
وسوف يتناول هذا البحث محورين أساسيين هما: المحور الأول: استراتيجية تنال القمر:

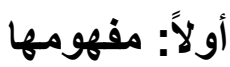

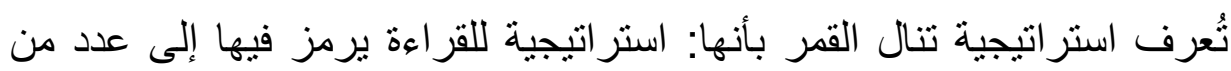

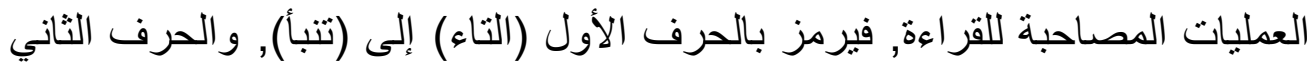

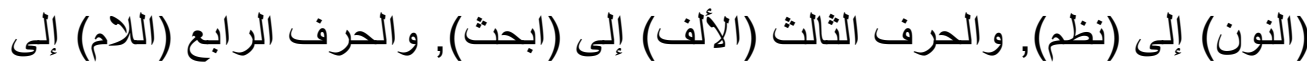

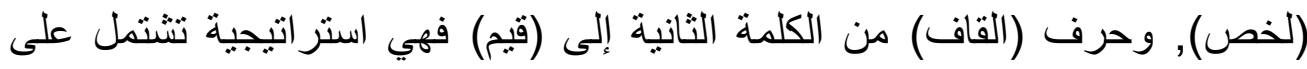

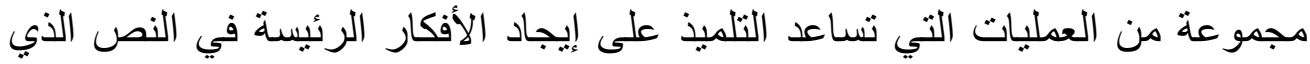

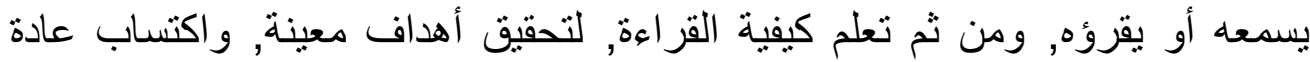


استراتيجية تنال القمر ودورها في تدريس الأحاديث النبوية الثريفة لتلاميذ المرحلة الإعدادية الأزهرية أ أشاذلي أحمد محمد أحمد علي الأية

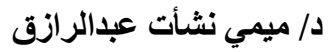

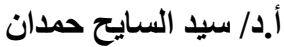

القراءة الذاتية المستقلة المعتمدة على الثقة بالذات, والمتفاعلة مع المقروء (إلهام بنت عبدالعزيز الغنام ,2013, 10).

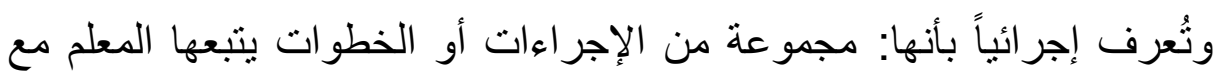
تلاميذه بهذف الوصول للأفكار الرئيسة, وتنظيمها لإجراه على شكل خريطة معرفية, وتلخيصها, ومقارنتها.

ثانياً: خطوات استراتيجية تنال القمر:

1 - تنبأ: يقوم التلميذ في هذه الخطوة بتأمل الصور الموجودة في الكتاب ويتنبأ بعنوان

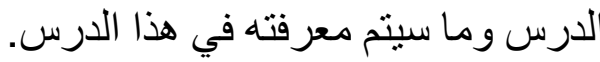
r- نظم: يقوم التلميذ بتنظيم خبراته السابقة وذللك للمساعدة في تحديد طريقة فيقة البحث الصحيحة وما سيقوم به لمعرفة ما سيتم تعلمه خلال الحصة الدر اسية.

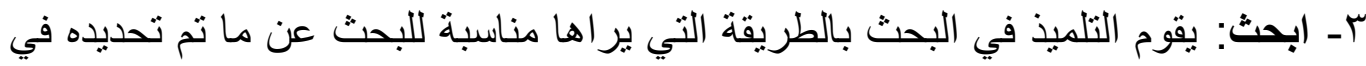
الخطو ات السابقة وهنا يكون التلميذ هو المسؤول عن تعلمه وتحديده للمعلومات المبات الموجودة.

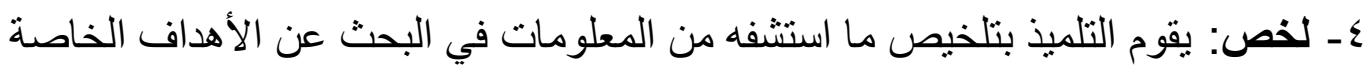

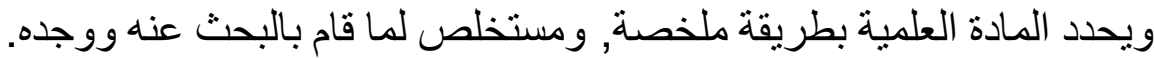

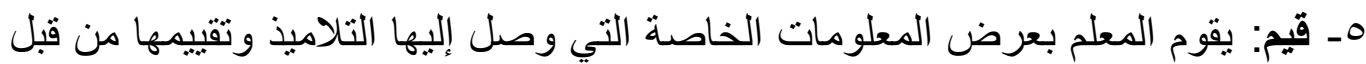

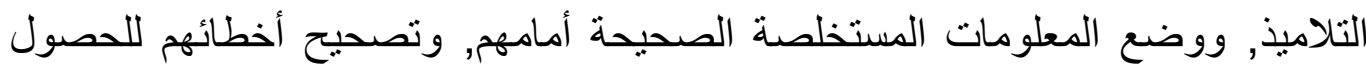

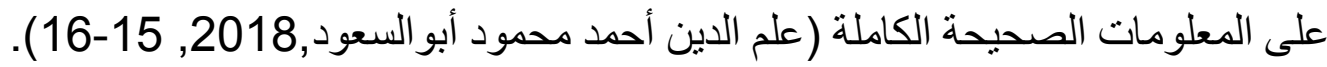

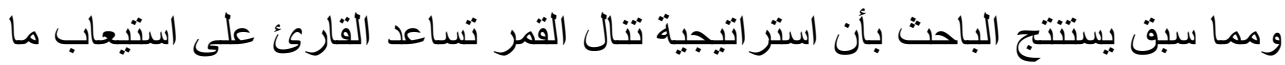
يقرؤه, ويحتفظ بأكبر قدر من المعلومات في ذاكرته ليتمكن من توظيف واستئه استخدام هذه المعلومات عند احتياجها لاحقاً حيث أنه في نهاية التدريس بالاستر اتيجية يجد التهن التلميذ نفسن فئه

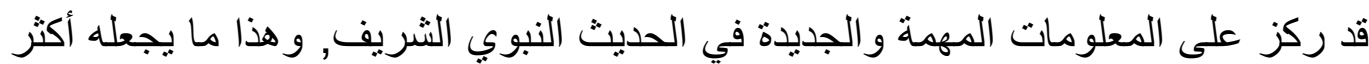
تركيزاً, و استيعاباً, وشعوراً بالإنجاز .

\section{ثالثاً: مميزات استراتيجية تنال القمر:}

تتمثل مميز ات استر اتيجية تنال القمر فيما يلي:

$$
\text { ا - تدريب التّّلاميذ على التعامل مع الكتاب المدرسي. }
$$

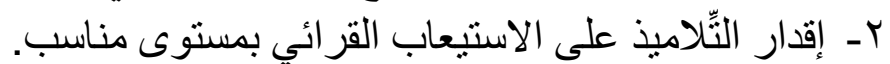

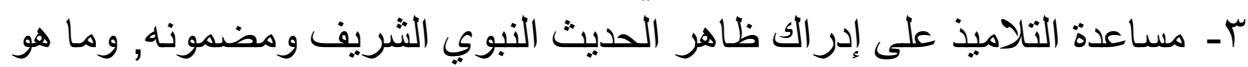
أبعد من المضمون الكائن في الحديث الندي النبوي الثريف. 
استراتيجية تنال القمر ودورها في تدريس الأحاديث النبوية الثريفة لتلاميذ المرحلة الإعدادية الأزهرية أ أشاذلي أحمد محمد أحمد علي الأية

ع - تشجع التلاميذ على الاعتماد على الذات وتمنحه فرصة لتعليل إجاباته.

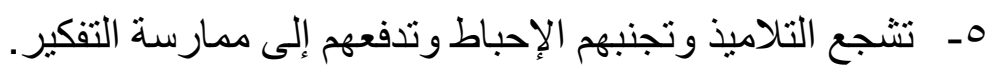

رابعاً: دور المعلم في استراتيجية تنال القمر: يتمثل دور المعلم في استر اتيجية تنال القمر فيما يلي:

1 - يقوم المعلم بعرض العنوان أو الجملة الرئيسية ويوجه التلاميذ إلى قراءتها

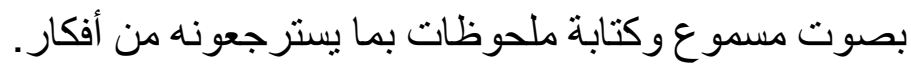

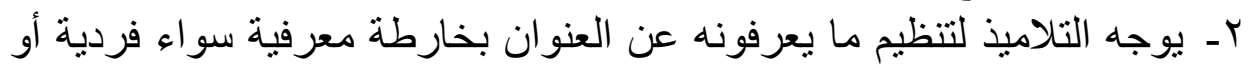

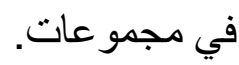
r- يقوم المعلم بتوزيع نسخ من الحديث النبوي الثريف على التنلاميذ .

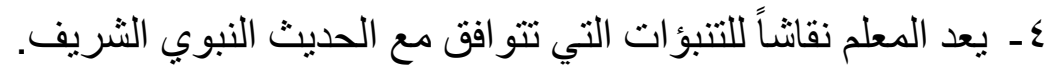
0ـ يقود المعلم المناقثات مع التلاميذ فيما كتبوه.

خامساً: دور المتعلم في استراتيجية تنال القمر: يتمثل دور المتعلم في استراتيجية تنال القمر فيما يلي: 1- يقوم التلاميذ بإيجاد الأفكار الرئيسة في الحديث النبوي الثريف الذي يسمعه أو

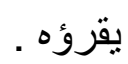

r- يتعلم التلاميذ كيفية القر اعة لتحقيق أهداف معينة. بـ اكتساب عادة القر اعة الذاتية المستقلة. ع - زيادة الثقة بالذات و التفاعل. 0ـ يقوم التلاميذ فر ادى أو في مجموعات لتألكوين خارطة معرفية لأفكار الحديث النبوي الثريف. 7- يقارن التلاميذ خر ائطهم المعرفية بالتبادل مع خر ائط المجمو عات الأخرى. سادساً: أهمية استراتيجية تنال القمر: تتمثل أهمية استر اتيجية تنال القمر فيما يلي: ا - تضفي على الفصل الصفي مزيداً من الفاعلية و النشاط. r- تقوي القدرة على الاستيعاب, و إعمال القدرات العقلية. 
استراتيجية تنال القمر ودورها في تدريس الأحاديث النبوية الثريفة لتلاميذ المرحلة الإعدادية الأزهرية

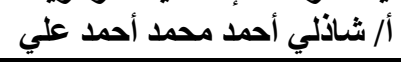

r- تعود التلاميذ على الاستقلالية في القراعة . ع - تمكن التلاميذ من البحث عن الأفكار, وتخلق لديهم الثقة بالنفس(خالد ياسين

$$
\text { الصيداوي, 1015, 10) }
$$

وبذلك يتضح أن أهمية استر اتيجية تنال القمر تتمثل في:

جعل التلاميذ عصباً للعملية التعليمية, وتتمي لايهم مهارة القر اءة. تنمي لدى التلاميذ مهار ات التفكير الناقد , و الابداعي, واعليدي والابتكاري. تساعد هذه الاستر اتيجية على فهم الحديث النبوي الثريف عبر التنبؤ بالأفكار , ورسم الخرائط المعرفية قبل عنوان الحديث التئ النبوي الثريف وبعده, وتقييم أعمال التلاميذ وخصوصاً في المر احل المتوسطة. تساعد استراتيجية تنال القمر في تغيير نظرة التلاميذ إلى القراءة, وتزيد

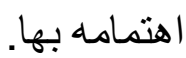
دفع التلاميذ إلى ممارسة نشاطات متعددة عبر العمل الجماعي وتنمية روح

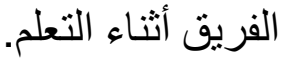

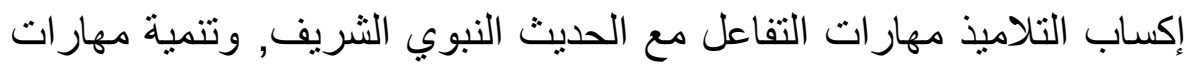

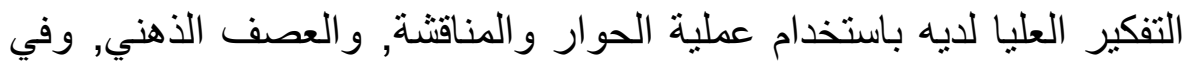
عملية التنبؤ, و التفكير , والإبداع, واسئه والتقييم.

\section{المحور الثاني: تدريس الأحاديث التبوية الثريفة:} أولاً: مفهوم الحديث النبوي الثريف:

يُعرف الحديث لغةً بأنه: نقيض القديم, والحديث: الجديد من الأشياء, والحديث

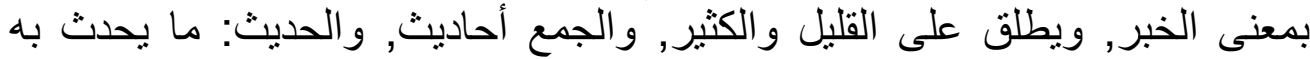
المحدث, وقد حدثه الحديث وحدث بها, ورجل حديث أي كثير الحديث (ابن منظور ,

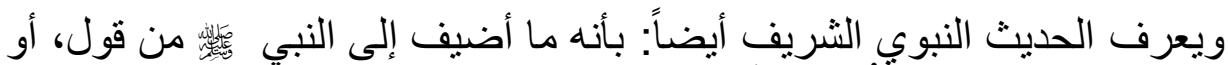

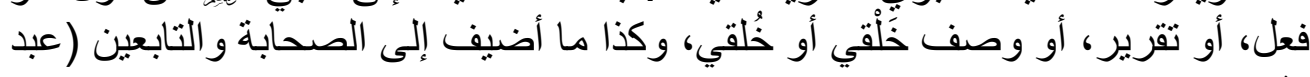

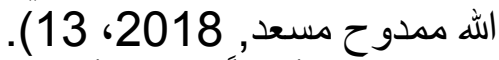

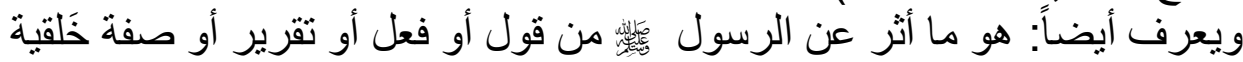
أو خُلقية. 
استراتيجية تنال القمر ودورها في تدريس الأحاديث النبوية الثريفة لتلاميذ المرحلة الإعدادية الأزهرية

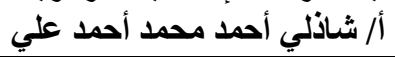

والحديث النبوي الثريف قد يكون نبوياً أي من كلام الرسول ئس

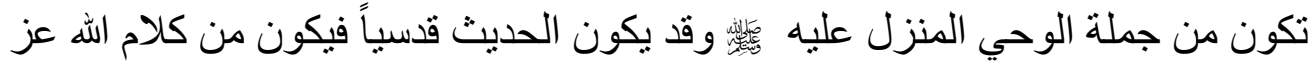

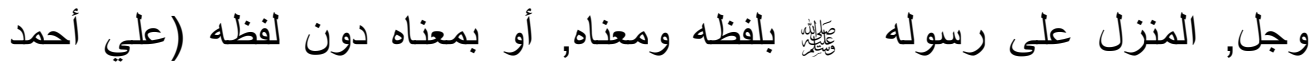

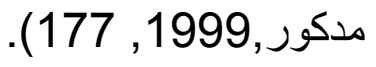

وبذلك يتضح أن الحديث النبوي الثريف مصدراً لتوجيه السلوك الديني, ومنهجاً

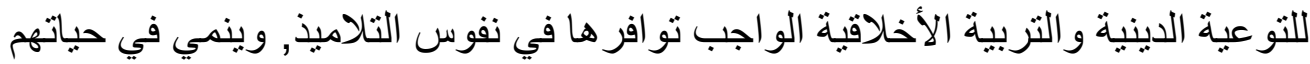
اتجاهات إيجابية, وكما يزود التلاميذ بالفهم الصحيح لأصول الصئه الإسلام و عقيدنه

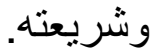

\section{ثانياً: أهمبة الحديث النبوي:}

أن أهمية الحديث النبوي الثريف تكمن في النقاط التالية:

اـ أن الحديث النبوي الثريف يبرز خصائص المنهج الإسلامي في شموليته، وتو ازنه، وتيسيره، ووسطيته.

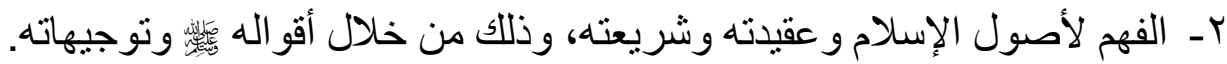
r- أن الحديث النبوي الثريف مصدر لتوجيه السلوك الديني في كل حالاته، عبادةً، و أخلاقًا، ومعاملاتً، وطاعةً لله عز وجل، وخدمةً للمجتمع وللحياة بصفة عامة. عـ فهم روح الشريعة الإسلامبة فهمًا صحيحًا يؤدي إلى التطبيق الصحيح لدين الله تعالى، ومعالجة المشاكل، و المستجدات معالجة سليمة بعيدة عن التساهل المذموم، و التشدد الممقوت.

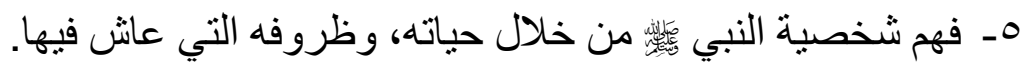

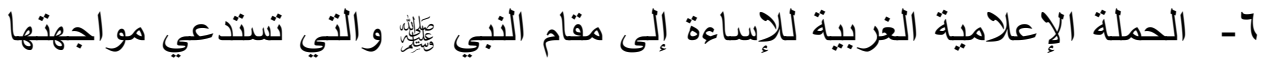
عن طريق دراسة الحديث النبوي الثريف، وذللك لكي يكون سدًا منيعاً أمام

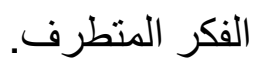
V- الحديث النبوي الثريف منهج للتوعية الدينية والتربية الأخلاقية الواجب نو افرها في نفوس التلاميذ، مما يساعد على غرس القيم الدينية في نفوس الناثئة، وتتمية 
استراتيجية تنال القمر ودورها في تدريس الأحاديث النبوية الثريفة لتلاميذ المرحلة الإعدادية الأزهرية أ أشاذلي أحمد محمد أحمد علي الأية

القيم الخلقية في سلوكهم، وذلك من خلال دراسة الحديث النبوي (سعيد عبد الله

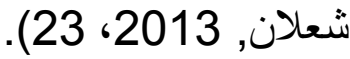

وبذلك يتضح أن أهمية الحديث النبوي الثريف: يبرز خصائص المنهج الإسلامي

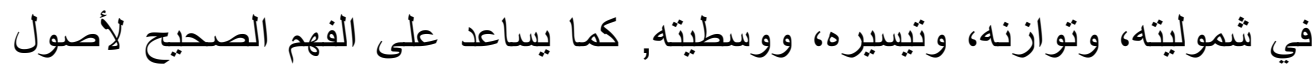

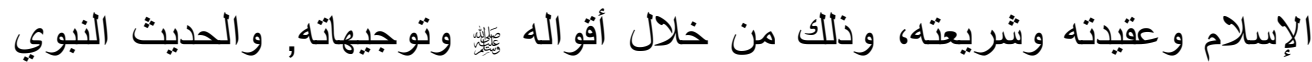

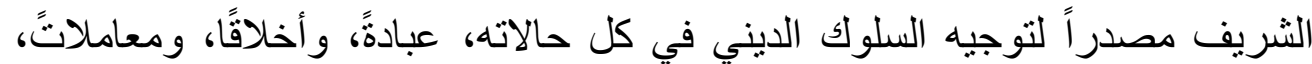

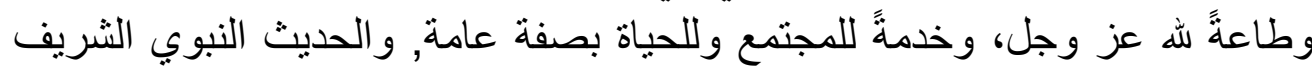

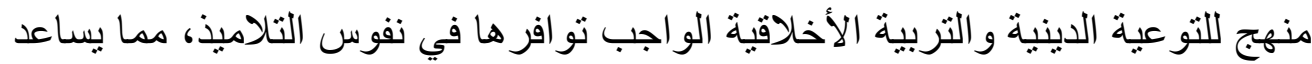

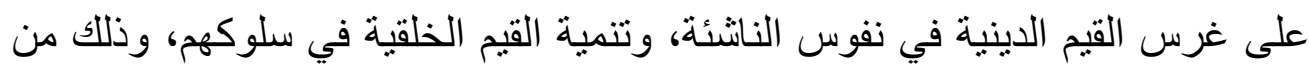
خلال در اسة الحديث النبوي الثريف.

ثالثاً: أهداف تدريس الحديث النبوي الشريف: تتمنل أهداف تدريس الحديث النبوي الثريف فيما يلي:

ا - إتقان قراءة الحديث النبوي الثريف, وضبط حركاته وسكناته وإظهار المعنى في قراعة بانه.

r- سلامة الفهم لمعاني الحديث النبوي الثريف, بالاعتماد على قواعد اللغة العربية, و على آيات القرآن الكريم, و على الأحاديث النبوية الثريفة الأخرى النيف, التي توضح الصورة الذهنية للحديث النبوي الثريف المشروح وعل وتحدد أبعادها, وتوسع آفاقها.

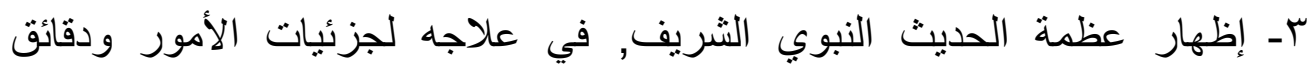

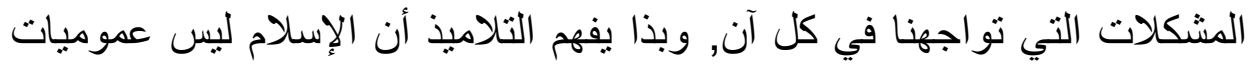

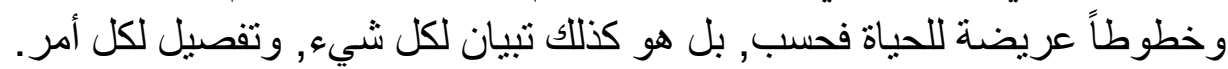

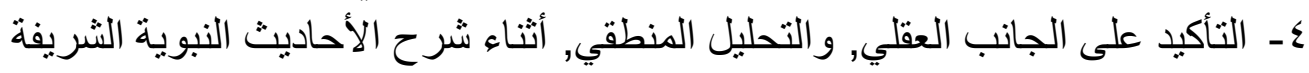

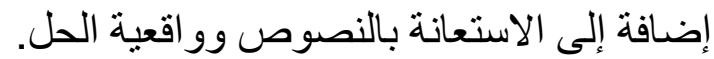

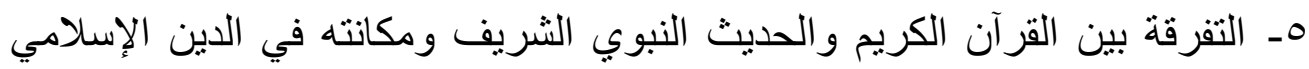
كمصدر ثان للتشريع الإسلامي. 7- التعرف على الأحاديث النبوية الثريفة من حيث طبيعتها وأنو اعها, و أهم أعلامها وطريقة تدوينها(حسن شحاتة, 1994, 161-160).

و الحديث النبوي الثريف يهدف إلى تزويد التلاميذ بالمفاهيم الدينية الصحيحة,

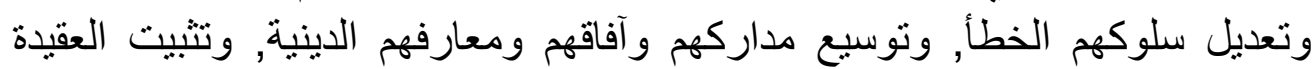


استراتيجية تنال القمر ودورها في تدريس الأحاديث النبوية الثريفة لتلاميذ المرحلة الإعدادية الأزهرية

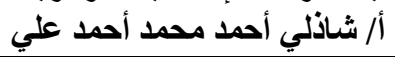

الدينية في نفوس التلاميذ, وحثهم على العادات الحسنة, و الأخلاق الحميدة, وحمايتهم

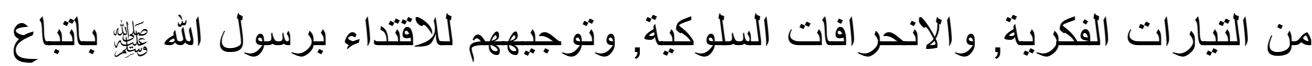

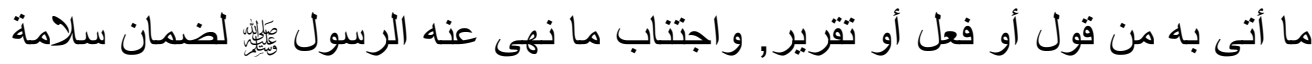

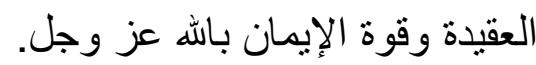

رابعاً: وظائف الحديث النبوي الثريف التربوية: الوظيفة الأولى: التبليغ الأمين الكامل لرسالة الإسلام:

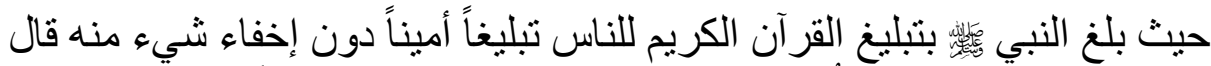

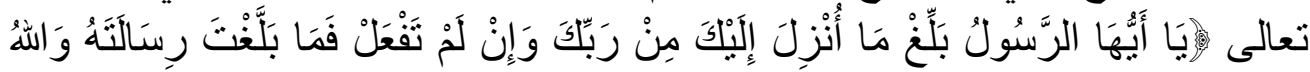

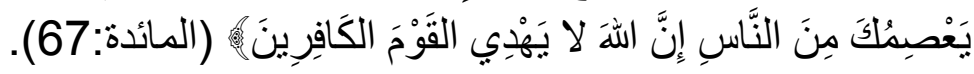
الوظيفة الثانية: توضيح المنهج التربوي الإلهي:

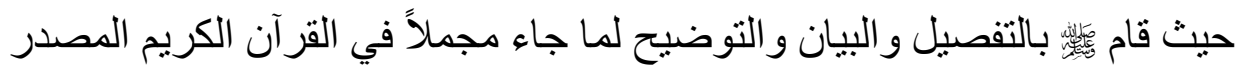

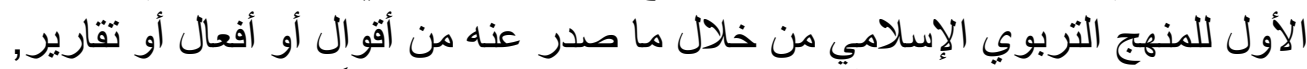

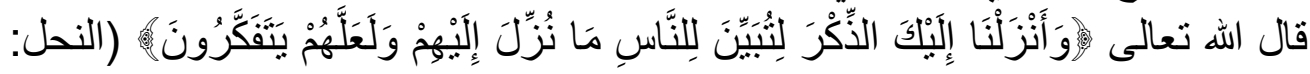

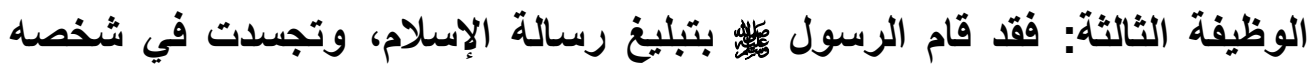
الكريم والثريف:

وذلك من خلال ما ظهر في أقواله و أفعاله وتقاريره, وما اتصف به من أخلاق حميدة وصفات كريمة, عاثها ئس في جميع مر احل حياته بصدق و أمانة و إخلاص, وقد وصفت ذللك أم المؤمنين السيدة عائشة رضي الله عنها قائلةً:(كان خُلقه القرآن).

\section{الوظيفة الرابعة: التوجيه والإرشاد والتربية:}

كان الرسول كل فضيلة, وتربية لهم على أحكام الإسلام ومعانيه وبناء لشخصياتهم بناءً إيمانياً شاملاً لجميع جوانب الثخصية السوية في أبعادها العقلية والروحية و الجسمية والاجتماعية و النفسية والأخلاقية (علي خليل مصطفى ابو العينين, 1988, 145). 
استراتيجية تنال القمر ودورها في تدريس الأحاديث النبوية الثريفة لتلاميذ المرحلة الإعدادية الأزهرية

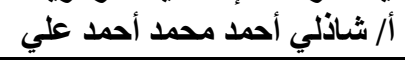

وقد أطاعه المسلمون وتقبلوا ما جاء به واقتدوا به في جميع أحواله و أفعاله

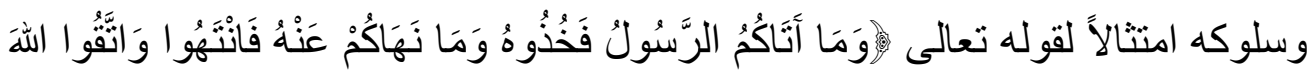

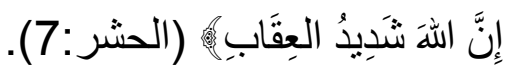

الوظيفة الخامسة: الاعوة:

أن الرسول ئس كان يدعو باللين, و الرفق, و الحكمة, و الموعظة الحسنة (عبدالحميد

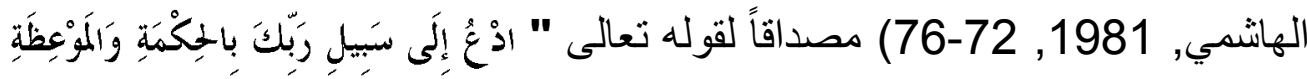

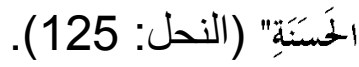

خامساً: أسس تدريس الأحاديث النبوية الثريفة: يمكن توضيح أسس تدريس الأحاديث النبوية الثريفة فيما يلي: 1ـ التهيئة الجيدة للموضوع و الإلمام بأهدافه, و الربط بين ما تحتوي عليه الأحاديث و الآيات القر آنية.

r- توجيه التلاميذ إلى كيفية التفرقة بين الحديث الصحيح وغير الصحيح بإمداده بالوسائل و الطرق التي تمكنه من ذللك و إرشادهم لمصادر الأحاديث الصحيحة. r- أن يفرق بين القرآن الكريم, و الحديث القدسي, و الحديث النبوي الشريف, وأهميته كمفسر لأحكام القرآن المجملة, حتى لا يختلط الأمر في ذهن التلاميذ, مع بيان مكانه كموجه لسلوك التلميذ في حياتهم العامة و الخاصة. ع - توجيه أنظار التلاميذ إلى المعاني التي تشتمل عليها الأحاديث النبوية الثريفة, وكيفية استتباط الأحكام و القو اعد من الأحاديث النبوية الثريفة بأنفسهم. 0- ينمي ميول التلاميذ الدينية للأحاديث النبوية الثريفة, وحفظها و الإلمام بها بأكبر عدد ممكن منها بما يتناسب مع مر احل حياتهم التعليمية, وربط الحديث النبوي الشريف بمشكلاتهم الو اقعية, وكيفية مو اجنها أسوة برسول الله (162,1994 
استراتيجية تنال القمر ودورها في تدريس الأحاديث النبوية الثريفة لتلاميذ المرحلة الإعدادية الأزهرية

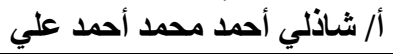

سادساً: العلاقة بين استراتيجية تنال القمر وتدريس الحديث النبوي الثريف:

تسهم هذه الاستراتيجية في مساعدة المتعلم على كيفية قراءة الحديث النبوي

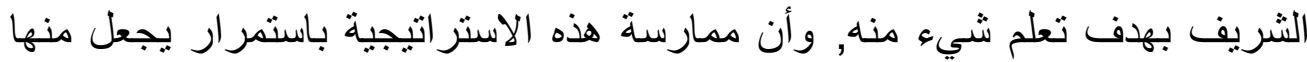

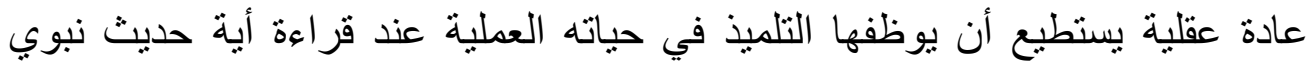
شريف, أو مقال, أو أية مادة أخرى, وتزيد من نقة الته التلميذ بنفسه بمساعدته على كيفية الوصول إلى المعلومات الواردة في الحديث النبوي الثريف. 
استراتيجية تنال القمر ودورها في تدريس الأحاديث النبوية الثريفة لتلاميذ المرحلة الإعدادية الأزهرية أر شاذلي أحمد محمد أحمد علي الأية

ابن منظور , لسان العرب, ط 1, المؤسسة المصرية العامة للتأليف و الترجمة, القاهرة.

الخامسة صالح سليمان العيد (2016). أثر استر اتيجية تنال القمر في تنمية مهار ات الاستيعاب القر ائي لدى طالبات الصف الأول المتوسط في مدينة حائل في المملكة العربية السعودية, در اسات عربية في التربية و علم النفس, العدد

$$
\text { (78), اكتوبر } 2016 .
$$

إلهام بنت عبدالعزيز الغنام (2013). تشجيع القراءة العربية, بحث مقدم اللمؤتمر الدولي الثاني للغة العربية, كلية الآداب, جامعة الملك فيصل, المملكة العربية السعودية.

ايناس جهاد سلمان (2016). أثر استر اتيجية تنال القمر في مهار ات ما ور اء المعرفة في مادة علم الأحياء لدى طالبات الصف الر ابع العلمي, مجلة البحوث

$$
\text { التربوية و النفسية, ص 300- 321. }
$$

حسن شحاته (1994). تعليم الدين الإسلامي بين النظرية والتطبيق, ط 1, مكتبة الدار العربية للكتاب, القاهرة.

خالد ياسين الصيداوي (2015). أثر استخدم استر اتيجية تنال القمر على تنمية مهار ات الفهم القرائي لدى تلميذات الصف الرابع الأساسي, رسالة ماجستير , كلية التربية, الجامعة الإسلامية غزة. 
استراتيجية تنال القمر ودورها في تدريس الأحاديث النبوية الثريفة لتلاميذ المرحلة الإعدادية الأزهرية أر شاذلي أحمد محمد أحمد علي الإعدية

رهيف ناصر علي العيساوي, و أحمد جاسب يوسف الساعدي (2012). استر اتيجية

تنال القمر و أثر ها في تنمية مهار ات القر اعة الجهرية عند تلاميذ المرحلة

الابتدائية, مجلة العلوم التربوية والنفسية, العدد(94), ص 207 - 262.

سعيد عبداله سعيد الشعلان (2013). تطوير منهج الحديث و الثقافة الإسلامية لطلاب المرحلة الثانوية في المملكة العربية السعودية في ضوء حاجات الطلاب ومشكلاتهم, رسالة دكتور اه, كلية التربية, جامعة أم القرى. صوفيا فيصل الهياجنة, شادية أحمد التل (2017). فاعلية استر اتيجيتي التساؤل الذاتي وتنال القمر في تنمية الاستيعاب القرائي وما وراء الاستيعاب القرائي, جامعة

$$
\text { اليرموك, الأردن, }
$$

عبدالحميد الهاشمي (1981). الرسول العربي المربي, ط 1, دار الثقافة للجميع, دمشق.

عبدالله ممدوح مسعد (2018). الاستشهاد بالحديث النبوي في معجم "تاج اللغة وصحاح العربية للجو هري", در اسة تحليلية, رسالة ماجستير, كلية الآداب،

جامعة طنطا.

عبداله نعمة الثمري (2010). تطبيق ثلاثة أساليب للتعلم النشط في تدريس التربية الإسلامية لطلاب الصف التاسع بدولة الكويت و أثر ها في تحصيلهم وتفكير هم

الإبداعي, رسالة ماجستير, كلية العلوم التربوية, جامعة الثرق الأوسط

$$
\text { للار اسات العليا, عمان. }
$$

علم الدين أحمد محمود أبو السعود (2018). أثر توظيف استر اتيجية تنال القمر في تنمية مهار ات التفكير التأملي في مادة العلوم و الحياة لدى تلميذات الصف الر ابع الأساسي بغزة, رسالة ماجستير, كلية التربية, الجامعة الإسلامية بغزة. علي أحمد مدكور (1999). منهج تدريس العلوم الشرعية, ط 1, دار الشواف,

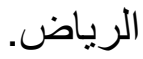


استراتيجية تنال القمر ودورها في تدريس الأحاديث النبوية الثريفة لتلاميذ المرحلة الإعدادية الأزهرية

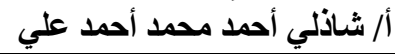

علي خليل مصطفى أبو العينين (1988). القيم الإسلامية و التربية, ط 1, مكتبة إبراهيم الحلبي, المدينة المنورة.

ماجد زكي الجلاد (2011). تدريس التربية الإسلامية, ط 1, عمان, دار المسيرة. محسن علي عطية (2008). الاستر اتيجيات الحديثة في التدريس الفعال, دار صفاء,

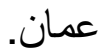

محمد صلاح الدين علي مجاور(1976). تدريس التربية الإسلامية أسسه وتطبيقاته

$$
\text { التربوية, ط 1, دار القلم, الكويت. }
$$

محمد عبداله حسين الحازمي (2013). تربية المر أة عند بن الجوزي ومدى الاستفادة منها في الو اقع التربوي المعاصر , رسالة ماجستير , كلية التربية, جامعة أم

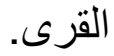

ياسر خلف رشيد الثجيري, ومناف جبير محمد الفهداوي (2013). أثر استر اتيجية تنال القمر في فهم المقروء لاى طلاب الصف الثاني المتوسط في مادة التربية

$$
\text { الإسلامية, مجلة جامعة الأنبار للعلوم الإنسانية, ص 1-49. }
$$

Adeniyi, F. A (2000)."Developing Reading Comprehension Secondary School Students Through Teacher Designed Vocabulary Context and The use of Dictionary ".Horin journal of Education Nigeria.

Raphael, Taffy E .and johnston,Mary and Pocius , Chery

L and Highfield, Kathy and George, Mari Anne (2001)."Questioning " Literacy in America : An Encyclopeda Barbara Guzzetti (ED). Santa

Barbar,CA :ABCCLIO Puplishers. Oakland ,P11. 